\title{
En la bárbara gentilidad de aquella tierra: Indígenas y diplomacia borbónica en la frontera del Misisipi en las tres últimas décadas del siglo XVIII
}

\author{
Amidst the Barbarous Heathendom of that Country»: Native \\ Americans and Bourbon Diplomacy in the Mississippi \\ Borderlands in the Last Three Decades of the $18^{\text {th }}$ Century
}

\author{
Izaskun Álvarez Cuartero \\ ORCID iD: https://orcid.org/0000-0002-2828-4581 \\ Universidad de Salamanca, España \\ Alejandro García Malagón \\ ORCID iD: https://orcid.org/0000-0002-9828-0690 \\ Universidad de Salamanca, España
}

Este artículo analiza los modos de relación que los grupos indígenas de las zonas fronterizas de Florida occidental y Luisiana entablaron con los enclaves españoles del curso inferior del río Misisipi durante las tres últimas décadas del siglo XVIII. Para ello revisamos el uso que se hizo del regalo como instrumento diplomático y de control, de compra de voluntades y de prestigio, destinado a modelar las pautas de comportamiento del indígena en una estrategia de contención de las autoridades españolas frente a la política de frontera desplegada por el gobierno estadounidense.

PalabRas Clave: Diplomacia borbónica; Frontera; Relaciones Indígenas; Regalo; Siglo XVIII.

This article aims to analyze the types of relationship established between the native population of Louisiana and West Florida borderlands and the Spanish enclaves in the Lower Mississippi River during the last three decades of the $18^{\text {th }}$ century. It particularly examines how Spanish authorities used gifts as a diplomatic tool towards indigenous people, to control and gain prestige between them, as well as purchase their goodwill; that strategy would enable Spanish representatives to tailor their behavior in order to contain the border policy displayed by the American government.

KEYwords: Bourbon diplomacy; Borderlands; Native American Relationships; Gift; $18^{\text {th }}$ Century.

Copyright: (C) 2021 CSIC. Este es un artículo de acceso abierto distribuido bajo los términos de la licencia de uso y distribución Creative Commons Reconocimiento 4.0 Internacional (CC BY 4.0). 
Señor, todo se halla con quietud y sosiego: los habitantes e indios, cada día más aficionados a la nación española, pongo de mi parte todos los medios posibles.

José de Orieta $^{1}$

Hablar de fronteras en la América del Norte de finales del siglo XVIII nos lleva a adentrarnos en un terreno movedizo, de semánticas variables y multiplicidad de sociedades, culturas y relatos. Nuestra intención en este artículo es analizar las relaciones que las autoridades españolas entablaron con los grupos indígenas en el curso inferior del río Misisipi, una zona deseada por todos y dominada por unos pocos, y revisar el uso que se hizo del regalo como instrumento diplomático, de control, de compra de voluntades y de prestigio en la estrategia de contención que la monarquía hispánica desplegó frente a la política expansionista del gobierno estadounidense.

Respecto al título, conviene aclarar que nuestro estudio está dedicado a las regiones fronterizas del valle del Misisipi con Florida occidental y Luisiana, comprendidas en la frontera Norte del imperio español en América y pertenecientes a la jurisdicción de la capitanía general de Cuba, parte, a su vez, del virreinato de Nueva España. No estaban integradas en el gran Norte o septentrión novohispano, ${ }^{2}$ un vastísimo territorio de límites oscilantes, administrado por la comandancia general de las Provincias Internas y con una fuerte presencia de naciones indias, como apaches y comanches. ${ }^{3}$ Los límites del imperio español fueron cambiantes en esas latitudes, sobre todo en la región de Luisiana; las fricciones con Estados Unidos la convirtieron en una ficción jurídica, sometida al escrutinio diplomático, con resultados lesivos para España: el control que ejercía a distancia era casi nominal y no bastó para frenar las medidas de presión y desgaste de su rival. Para el gobierno estadounidense, sus dominios abarcaban desde la cuenca occidental del río Misisipi hasta la divisoria de aguas de las Rocosas y el sudeste del río Bravo.

1 José de Orieta al capitán general Luis de Unzaga y Amezaga, 26 de enero de 1771, Archivo General de Indias, Sevilla (AGI), Papeles de Cuba, 107.

2 Alfredo Jiménez $(2006,80)$ define el Gran Norte como «los territorios situados más allá del Valle de México que estuvieron bajo jurisdicción española de manera más o menos efectiva, y durante un tiempo largo se consideraron frontera en el sentido amplio del término».

3 Constituida en 1776, estaba formada por las provincias de Nueva Vizcaya, Nuevo México, Nuevo León, las Californias, Sonora, Sinaloa, Nuevo Santander, Coahuila y Texas; correspondería aproximadamente a los actuales estados mexicanos de Baja California, Baja California Sur, Durango, Chihuahua, Sonora, Sinaloa, Coahuila, Nuevo León, Tamaulipas, Zacatecas y los estadounidenses de California, Georgia, Carolina del Norte y del Sur, Alabama, Mississippi, Virginia, Kentucky y Tennessee. 
Para realizar este trabajo se ha revisado especialmente la correspondencia entre los capitanes generales de Cuba y los gobernadores de Florida y Luisiana, y las comunicaciones internas entre los comandantes de los puestos y sus respectivos gobernadores, además de las relaciones de bienes y correspondencia de los contadores de las intendencias. ${ }^{4}$

\section{Una semántica imprecisa: la frontera}

El término frontera presenta una complejidad en su definición. En primer lugar, hay que precisar que en español carece de los matices que posee en inglés - derivados del contexto en que nos encontramos y de la interpretación que hizo Frederick Turner a finales del siglo XIX,$-{ }^{5}$ a pesar de su afinidad etimológica, compartida también con el francés - frontera, frontier, frontière - . En principio, procede del «latín frons, frontis, que significa la frente o la parte delantera de algo»,${ }^{6}$ de donde deriva la definición de frontera del Diccionario de Autoridades (1732): «raya y término que parte y divide los reinos por estar el uno frontero del otro», y el adjetivo fronterizo, voz que conceptualiza lo problemático de la frontera; más adelante (en el Diccionario académico de 1803) se redefine como «el extremo, o confín, de un estado o reino», significado que se ha seguido simplificando hasta el actual «confín de un estado». ${ }^{7}$ En consecuencia, nos referimos a una zona periférica respecto a los centros de poder, un territorio entre lo conocido y lo remoto, en continua evolución, y un espacio conquistable donde se generan nuevos procesos de adaptación y los mecanismos de cambio resultan diferentes. A diferencia de border y boundary, la idea de lejanía e incertidumbre es la que se ha transferido al inglés, donde frontier es lo que

4 De forma aproximada, este artículo sigue el espacio de tiempo marcado por los gobiernos en Luisiana de Luis de Unzaga y Amézaga (1769-1777), Bernardo de Gálvez (1777-1785), Esteban Rodríguez Miró (1785-1791) y Francisco Luis Héctor de Carondelet (1791-1797), es decir, las tres últimas décadas del siglo XVIII. Sobre este periodo, véase Hoffman, 1992, 113-268.

5 «The American frontier is sharply distinguished from the European frontier - a fortified boundary line running through dense populations. The most significant thing about the American frontier is that it lies at the hither edge of free land», Turner, 1920, 3.

6 Taylor, 2007, 232.

7 Nuevo tesoro lexicográfico de la lengua española, s. vv. «frontero», «fronterizo». Disponible en http://ntlle.rae.es/ntlle/SrvltGUILoginNtlle [Consultado: 03/12/2019]. RAE, 2014, s. vv. «frontero». La cita en el Diccionario de Autoridades (1732), tomada de Alonso de Ovalle (Histórica relación del reino de Chile, 1646, lib. VIII, cap. 16), ilustra la negatividad del término: «No se les puede à estos Indios corregir sus vicios: así por ser sin comparación más altivos, como por estar de guerra y ser fronterizos». 
separaba a los colonos de las tierras del Salvaje Oeste. Desde esta perspectiva, el desarrollo de la sociedad americana parte continuamente de cero en la frontera, es un renacimiento perenne en palabras de Turner, un organismo que se reinventa y adapta continuamente. ${ }^{8}$

En 1921, Herbert E. Bolton acuñó el término Spanish borderlands en referencia al territorio entre Florida y California dominado por España; discípulo de Turner, Bolton examinó la importancia geopolítica del presidio y la misión en la frontera y constató la expansión española al norte del valle de México «in social, religious, economic, and even in legal customs», que contradecían la idea de que el «Oeste» fuera algo vacío o bárbaro. ${ }^{9}$ En opinión de David Weber, sus apreciaciones resaltaban la rigidez de la monarquía hispánica que «stifled initiative, individual liberty, and selfgovernment» y no supo ver la permeabilidad de la frontera, negando que «the frontier influenced Hispanic institutions and character». ${ }^{10}$

Tendencias historiográficas posteriores, especialmente la New Western History, rechazaron las tesis turnerianas y los estereotipos del «mito agrario» estadounidense para abordar el debate con una metodología interdisciplinar, aunque también se cuestionó su novedad y gregarismo. ${ }^{11}$ Más interés guardan para nuestro enfoque los historiadores de los borderlands, quienes en los años setenta comenzaron a indagar la intrahistoria de los habitantes de la zona para dar un giro «desde el estudio de las instituciones al estudio de la vida cotidiana, de las formas en que la herencia cultural de los pobladores se fue modificando y adaptando a las nuevas condiciones de vida». ${ }^{12}$ A destacar, el trabajo de Oakah L. Jones sobre el papel prominente que los paisanos y sus asentamientos jugaron en la expansión española hacia el Norte; en su opinión se volvieron «more self-reliant, more individualistic, less class conscious, and more conservative in their political outlook than the people of central New Spain».13

El proceder de estos españoles y la modulación de las instituciones fronterizas fueron definidos por el entorno natural y las relaciones humanas e, igualmente, su comportamiento afectó a la estructura interna de las poblaciones originarias con cambios económicos, sociales y culturales,

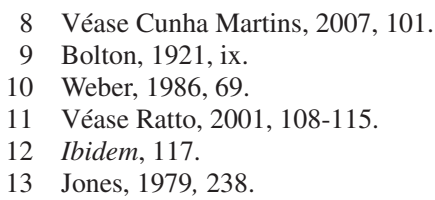


tratados en los estudios que subrayan la experiencia indígena. ${ }^{14}$ Weber señala que «the natures of these interactive cultures — both the culture of the invader and that of the invaded - combine with the physical environment to produce a dynamic that is unique to the time and place». ${ }^{15}$ Esta dinámica única es lo que origina «una multiplicidad de relaciones y de conexiones solapadas, una región de interacción, de influencia recíproca», según Bernd Schröter. ${ }^{16}$ Nos encontramos ante un entorno poblacional transitorio donde las relaciones se entretejen sin cesar generando modos de interconexión - pacíficos u hostiles - adaptados a las necesidades y posibilidades de cada momento y que favorece procesos transculturales y relaciones interétnicas múltiples.

El recorrido historiográfico del concepto frontera es mucho más extenso de lo que podemos analizar aquí. En lo que afecta a la frontera en el valle del Misisipi, proponemos definirla como una región alejada de la administración virreinal, con una existencia histórica transitoria, dependiente de variables diversas y una realidad transcultural; sus instituciones principales eran el presidio y la misión, herramientas creadas para controlar y consolidar el territorio adquirido y expandir las posesiones y el control en el Septentrión. Más que un límite, fue un lugar de encuentros coloniales, por lo que cabría entenderla como una zona de contacto de las que describe Mary Louise Pratt: un espacio donde «personas separadas geográfica e históricamente entran en contacto entre sí y establecen relaciones duraderas, que por lo general implican condiciones de coerción, radical inequidad e intolerable conflicto». ${ }^{17}$ A diferencia de las fronteras coloniales, de la zona de contacto emerge una yuxtaposición y el «centro de gravedad» se desplaza hacia el lugar y el momento en el que los individuos «coexisten en un punto» y se constituyen «en y a través de su relación mutua». ${ }^{18}$

\section{Regalar no es gratis: el regalo como institución de control social}

La doremática - del griego dorémata - hace referencia al favor, regalo, don, obsequio o donación, ${ }^{19}$ una práctica social que Marcel Mauss estudió

14 Véase Spicer, 1962.

15 Weber, 1986, 81.

16 Schröter, 2001, 366.

17 Pratt, 2010 [1992], 33.

18 Ibidem, 34.

19 Martínez Díaz de Guereñu, 2011, 14. Neologismo acuñado por el autor. 
ampliamente en la obra inaugural sobre el tema, Ensayo sobre el don, donde proporciona ejes interpretativos para comprender su influencia en los fenómenos de correspondencia, protección, lealtad y asistencia mutuas:

[L]o que intercambian no son solo bienes y riquezas, muebles e inmuebles, cosas económicamente útiles. Intercambian, ante todo, cortesías, festines, ritos, colaboración militar, mujeres, niños, danzas, fiestas, ferias en las que [...] la circulación de las riquezas no es más que uno de los términos de un contrato mucho más general y mucho más permanente. Por último, esas prestaciones y contraprestaciones se realizan de forma más bien voluntaria, a través de presentes o regalos [...]. Proponemos denominar todo esto sistema de prestaciones totales. ${ }^{20}$

Es este fenómeno un elemento diferenciador de las sociedades arcaicas, en el que se entremezclan instituciones religiosas, jurídicas y morales que suponen formas particulares «de la prestación y la distribución». ${ }^{21}$ En efecto, entre los pueblos indígenas del Norte, el don era un hábito simbólico que reforzaba la autoridad del líder y la identidad grupal, les inducía a seguir determinadas normas e interactuar con otras sociedades. La circulación del regalo se fusionaba, en cierta forma, con lo sagrado y producía momentos de sociabilización que sacralizaban prácticas morales. Ensayos filosóficos recientes dedicados a la teoría del gift economy proponen que el don provee de una esfera de libertad en contraposición a la lógica que representa el intercambio económico. Por ejemplo, Sharon Harvey no identifica el don con un regalo, ya que este permanece en la economía de cambio y, por ende, no implicaría deuda o devolución, ${ }^{22}$ lo trascendental es el vínculo que se establece a través de este sistema de donación e intercambio. Estas propuestas nos ayudan a comprender la importancia del reparto de los bienes entregados al jefe del grupo, quien los distribuye entre los individuos de su comunidad, fortaleciendo su cohesión y dotando de prestigio al líder, porque su acción es tenida como un acto de generosidad.

A finales del siglo XVIII, la mayoría de los pueblos indígenas norteamericanos «habían sido asimilados más que eliminados», recuerda Weber, pero muchos de ellos mantenían su independencia y se habían adaptado «de algún modo al mundo hispánico y viceversa». ${ }^{23}$ Se impulsan entonces

20 Mauss, 2009 [1925], 75.

21 Ibidem, 70.

22 Véase Harvey, 2012, 11.

23 Weber, 2007, 16. No siempre fue así y, en zonas de la Comandancia General de las Provincias Internas, las autoridades combatieron y diezmaron a los pueblos indios que atacaban los puestos españoles. 
medidas diplomáticas que buscan atraer al indígena y controlar a las poblaciones nativas autónomas; según Weber, se actuó «con renovada energía con el objetivo de conseguir la lealtad de los indígenas no sometidos que vivían en la periferia del imperio». ${ }^{24} \mathrm{~A}$ tal propósito, el regalo constituía una forma de interrelación eficaz, como se había comprobado en los territorios franceses y británicos, que podía sumarse a las dinámicas políticas que empleaban las autoridades españolas; se crearon, así, nexos de amistad que permitieron a los españoles intervenir en la vida de las comunidades indígenas con la intención última de ejercer el control sobre sus acciones.

En síntesis, interpretamos el uso del regalo en la frontera como un sistema binario de relaciones exógenas y endógenas. Las primeras fueron generadas por los españoles para comprar voluntades y como acción diplomática y las segundas para afianzar la posición de los respectivos jefes entre los integrantes de su clan.

\section{De los hombres blancos y las naciones indias}

La firma del tratado de París de 1763 ponía fin a la guerra de los Siete Años con cierto equilibrio entre las tres potencias europeas partícipes. En este mapa geopolítico, España y Gran Bretaña detentan la hegemonía sobre Norteamérica y se redefinen las áreas de dominio en la frontera en concurrencia con los indígenas. Como resume John Elliott:

Gran Bretaña retuvo Canadá, pero devolvió Guadalupe y Martinica a Francia; España, a cambio de la devolución de Cuba, cedió a los británicos Florida (la región entera al este del Misisipi), abandonó sus reivindicaciones sobre los bancos pesqueros de Terranova e hizo concesiones respecto a la tala de maderas de tinte a lo largo de la costa centroamericana; los franceses, para dorar la píldora a sus vecinos aliados, transfirieron a España su colonia de Luisiana, que ellos mismos ya no estaban en posición de defender. ${ }^{25}$

Un acontecimiento de gran trascendencia precipitó las transformaciones en la frontera norte: la revolución de las colonias británicas. Como habían hecho con anterioridad, los ingleses captaban a los indígenas para que sirvieran de defensa contra las pretensiones de los españoles, aliados de los

24 Weber, 1998, 148.

25 Elliott, 2006, 434-435. 
insurgentes, en Florida. Cabría preguntarse por qué los nativos apoyaron a los británicos. Quizás se debió a su forma de entablar relaciones con ellos, asumiendo sus instituciones de intercambio, como el regalo, para conseguir su cooperación. Durante la contienda, Bernardo de Gálvez ${ }^{26}$ se impuso en la Florida occidental y el tratado de París de 1783, que sancionaba la independencia de las Trece Colonias como los Estados Unidos de América, terminó ratificando la soberanía española en la península en detrimento de la Corona británica; pese a sus artimañas, Gran Bretaña perdió todas sus posesiones continentales, conservando solo las Bahamas y el libre acceso al Misisipi: «The Navigation of the River Mississippi, from its source to the Ocean shall forever remain free and open to the Subjects of Great Britain and the Citizens of the United States». ${ }^{27} \mathrm{Se}$ abre un nuevo panorama político, con la primera nación de América decidida a participar en la competencia territorial, que desembocará en la idea del Manifest Destiny. ${ }^{28}$

La libre navegación por el río era uno de los principales problemas para España. Aunque Gálvez había franqueado a los insurrectos el tránsito fluvial, la perspectiva cambió tras la independencia. La ascendente demografía en el Este, sus aspiraciones comerciales y el influjo del liberalismo persuadían a los colonos, incluso españoles, a expandirse hacia una zona apenas poblada como la Luisiana, ${ }^{29}$ una provincia para la que España implementó nuevas leyes e instituciones comerciales, pero que apenas podía «proporcionar un contexto dentro del cual la colonia prosperase, aunque sí podría sobrevivir pobremente» ${ }^{30} \mathrm{~A}$ este respecto, era prioritario deslindar las tierras a cada lado del Misisipi. Mientras que los españoles situaban el

26 Bernardo de Gálvez, gobernador interino de Luisiana desde 1776 y confirmado en el cargo en 1779, era el responsable de las políticas españolas en el periodo que nos ocupa. Posteriormente sería gobernador de Cuba (1786) y virrey de Nueva España (1786).

27 «Treaty of Paris», 9 de marzo de 1783, art. 8, National Archives, Washington, Perfected Treaties (1778-1945), 299805, f. 14v. Disponible en https://catalog.archives.gov/id/299805 [Consultado: 03/12/2019]. La excepción terminaría favoreciendo los intereses de los americanos en el área de influencia del río.

28 «O’Sullivan escribió en 1845 que era el Destino Manifiesto de los Estados Unidos expansionarse por el continente que la Providencia le había asignado. En dos palabras se encerraba la justificación para el avance inevitable de la frontera desde el Mississippi hasta las costas del Pacífico», Jiménez, 2001, 745.

29 Jack Holmes cifra la población de Florida Occidental y Luisiana en 42.375 habitantes hacia 1803; en Holmes, 1961, 637. Para el conjunto del territorio, los censos de la población americana (incluyendo esclavos) de 1790 y 1800 indican un total de 3.893 .635 y 5.627.790, respectivamente; en US Census Bureau, Census of Population and Housing, 1790 y 1800. Disponible en: https://www. census.gov/prod/www/decennial.html [Consultado: 23/12/2019].

30 Hoffman, 1992, 113. 
límite en los $32^{\circ} 22^{\prime} \mathrm{N}$ en paralelo al río Yazú —o Yazoo-, los estadounidenses querían extender sus posesiones al norte del paralelo $31^{\circ}$ y alcanzar la desembocadura del río para facilitar su comercio. ${ }^{31}$

\section{FIGURA 1}

\section{NUEVO MAPA DE BOLSILLO DE CARINGTON BOWLES DE LOS ESTADOS UNIDOS DE AMÉRICA (1784)}

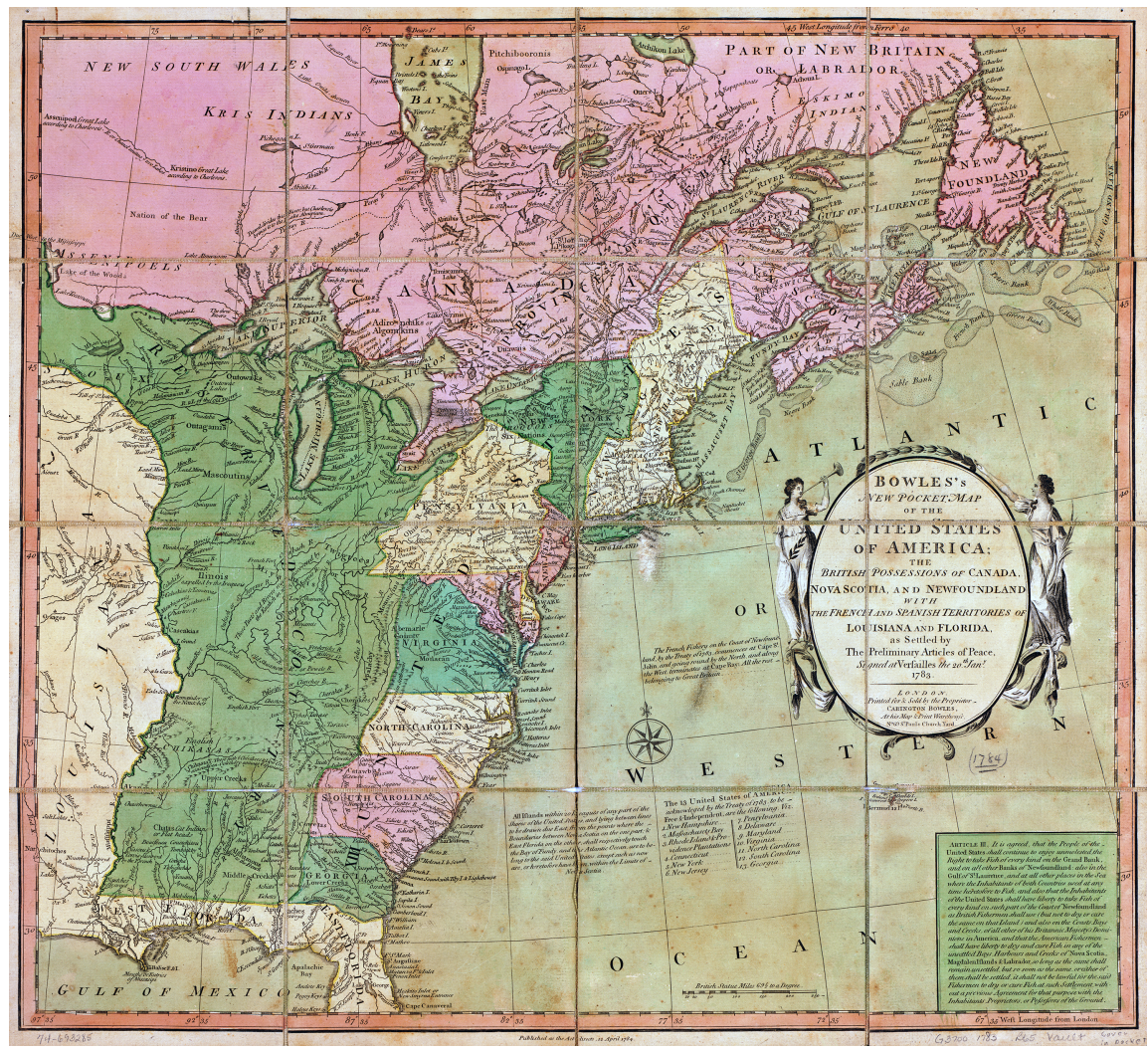

Fuente: Bowles's new pocket map of the United States of America; the British possessions of Canada, Nova Scotia, and Newfoundland with the French and Spanish territories of Louisiana and Florida as settled by the preliminary articles of peace, signed at Versailles the 20th January 1783, Londres, 1784. Library of Congress, Washington, D.C., Geography and Map Division, G3700 1783. B65. Disponible en: http://hdl.loc.gov/loc.gmd/g3700.ar074503 [Consultado: 10/12/2020].

31 Véase «Memorial to Diego de Gardoqui which concerns limits», 7 de diciembre de 1793, en Al Gobernador de la Habana remitiéndole documentos, AGI, Estado, 14, n. 50, ff. 1r-3v. Disponible en http://pares.mcu.es/ParesBusquedas20/catalogo/show/62393?nm [Consultado: 08/10/2019]. 


\section{FIGURA 2}

\section{«DISTRIBUCIÓN DE ESTABLECIMIENTOS, PUESTOS E INDIOS}

EN EL CURSO DEL MISISIPI» (C.1792)

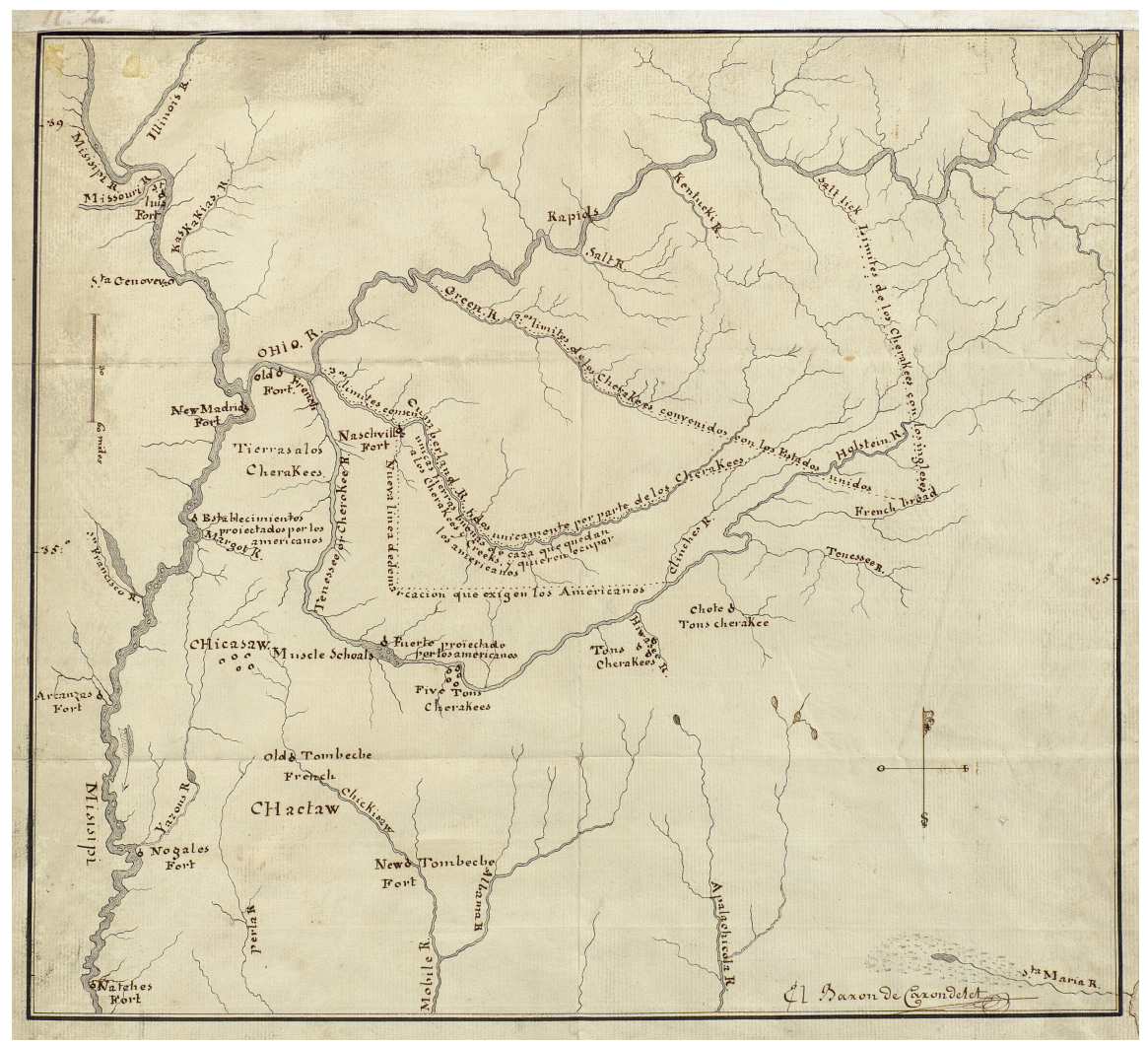

Fuente: «Cartas del barón de Carondelet, Gobernador Intendente de la Luisiana y Florida occidental, a la Secretaría de Estado, con otros documentos relativos a la cesión de los Nogales y a diversas tribus indias». España, Ministerio de Cultura y Deporte, Archivo Histórico Nacional, Estado, Colección mapas, planos y dibujos de Estado, 20.

La actitud de los nativos por mantener su autonomía jugaría un importante papel. La Corona reconocía los territorios de cada pueblo cuando aceptaban a su majestad católica como su único protector, una imprecisa manera de colonización de la que recelaban los estadounidenses. Tanto ellos como los españoles, además, imitaban las tácticas de aproximación que habían utilizado franceses e ingleses para tejer una barrera al este del 
Misisipi, aliándose con grupos indígenas de manera pacífica y preservando sus propios intereses contra los tejemanejes de los adversarios. Ejemplo de ello es el dosier que, en el verano de 1793, Luis de las Casas remitía al duque de la Alcudia - Manuel Godoy, entonces secretario de Estado- en la que reflejaba su desconfianza por la conducta desestabilizadora de lord Dunmore - gobernador de Bahamas - con los indios creek, aliados de los españoles ${ }^{32}$ comunicaba su preocupación por los tratos que había iniciado con Philatouche, jefe semínola afroindio que organizaba escaramuzas contra los estadounidenses y otros grupos y tenía tratos comerciales con unos y otros. ${ }^{33}$ La carta de Las Casas sirve para ilustrar el sentimiento español en la región, plagado de recelos, como se desprende de la correspondencia entre las autoridades coloniales y metropolitanas cuando se refieren a los «asuntos indios» y a la presencia de los «americanos» que amenazaban la «frontera».

Pero ¿quiénes eran estos indios con los que trataban los españoles y que ocuparon cientos de folios y dieron más de un quebradero de cabeza a la burocracia colonial? La bibliografía en español sobre las relaciones de frontera cuenta con interesantes aportaciones como las de Abelardo Levaggi o Carmen González; ${ }^{34}$ muy escasa si la comparamos con la abundante producción de la academia estadounidense, que ha dedicado sólidas investigaciones a desentrañar en clave antropológica, económica y política estos espacios. ${ }^{35}$ Esta literatura es coincidente a la hora de señalar que España utilizó a las naciones indias aliadas de los valles del Misisipi y del Arkansas como escudo ante el avance de los norteamericanos y como salvaguarda del territorio de Nueva España durante el gobierno de La Luisiana (17621800). ${ }^{36}$ La prosperidad de las colonias dependía más que nunca de su capacidad defensiva y, a largo plazo, era esperable que las políticas ilustradas reforzasen «la lealtad política, alimentando sentimientos de patriotismo en las comunidades del valle del Misisipi que debían jurar lealtad a la Corona». ${ }^{37}$

32 Las Casas al duque de la Alcudia, 10 de agosto de 1793, AGI, Estado, 14, n. 38, ff. 1r-8v. Lord Dunmore, último gobernador de la Virginia británica, fue el autor de la controvertida proclamación de 1775 que concedió la libertad a los esclavos a cambio de servir en su ejército.

33 Los semínolas pertenecieron a los creek hasta su desplazamiento al norte de Florida en 1715. Este grupo sufrió un interesante proceso de miscegenación por la mezcla con esclavos y con cimarrones. Se enfrentaron al Ejército estadounidense por esta cuestión y por las continuas ocupaciones de tierra y desplazamientos forzosos hacia las reservas.

34 González López-Briones, 1994, 11-37. Levaggi, 1998, 449-483. Veáse también Hilton, 2013, 227-236.

35 La presencia en la región de los indios timucua, semínolas, calusa, creeks, chactas o miccosukees ha sido estudiada, entre otros, por Hann, 1996; Juricek, 2010; Milanich, 1999, y O’Brien, 2002.

36 Véase Levaggi, 1998, 450.

37 Hilton, 2013, 230. 
Es interesante apuntar que, desde San Agustín, se remitían informes pormenorizados al Consejo de Indias, a través de La Habana, sobre asuntos indios referidos a España que se dirimían en Filadelfia —independientemente de los informes del embajador, Diego María de Gardoqui- ${ }^{38}$ como el tratado de paz entre los cheroquis y los Estados Unidos y los esfuerzos españoles para abortarlo.

En esta área, de alrededor de $440.000 \mathrm{~km}^{2}$, se concentraban tribus sedentarias y nómadas en busca de mejores posibilidades de subsistencia; su diversidad no facilitó la convivencia, con disensiones continuas entre los grupos. El valle sirvió de refugio para aquellas etnias que se alejaban de los conflictos que los blancos generaban sin reparar en sus habitantes originarios; la guerra de Independencia de los Estados Unidos, la presión de los colonos o las prácticas cinegéticas de los tramperos fueron motivos de peso para replegarse hacia lugares aparentemente tranquilos. Habitaban el valle desde tiempo atrás los quapaws, o indios arkansas, y sus viejos enemigos los chicachas (o chickasaw), cadodachos, quiraves, cheroquis, miamis o abenaquis; tribus de la Confederación de los illiniwek o illinois — tenidos por salvajes y belicosos-, como los peorias y kaskaskias; o los osages, que incursionaban para cazar y asaltar al resto de los grupos. ${ }^{39}$

Encontramos, por tanto, un escenario complejo, con indígenas habituados a las estrategias mercantiles y a negociar con extranjeros, que repartían su presencia en el territorio mediante puestos militares. Demandaban todo tipo de objetos europeos, como tejidos, sombreros, mantas, harina, municiones, rifles, pólvora, etc., y un eficaz mediador, el alcohol. ${ }^{40}$ Por ejemplo, en 1770, el comandante del puesto de Arkansas reclamó al gobernador de La Luisiana barricas de aguardiente porque «los salvajes [hallaban] extraño que no se les [diese] bebida siempre que [iban] al puesto». ${ }^{41}$ Las continuas luchas entre pueblos indios tan heterogéneos y el aumento repentino de pobladores motivaban escasez de comestibles, por lo que los comandantes

38 Gardoqui había sido el artífice de la ayuda económica y armamentística que se prestó a las Trece Colonias y el primer representante diplomático español ante Estados Unidos, entre 1784 y 1789.

39 González López-Briones, 1994, 11-37.

40 Una piragua podía transportar todo tipo de género: 1 casaca de escarlata galonada de plata, calzones, fusiles, cinta de lana, 45 cuchillos carniceros, 14 peines de boj, 12 pares de tijeras, 50 sacatacos, 300 piedras de chispa, 4 onzas y media de cinta encarnada de seda, 2 pares de zapatos, 2 pares de medias de hilo, 9 libras y media de bermellón, 48 eslabones, 150 agujas, 9 sombreros bordados en plata, 1 camisa guarnecida, en Efectos que contiene en la piragua Mr. Lambert por los Arkansas, 26 de enero de 1775, AGI, Papeles de Cuba, 107, f. 225.

41 Francisco Demazellieres, comandante del puesto de Arkansas, a Luis de Unzaga, gobernador de La Luisiana, 4 de marzo de 1770, AGI, Papeles de Cuba, 107, f. 60v. 
de los establecimientos tenían que arbitrar soluciones para preservar la calma, como se refleja en las muchas cartas de solicitud de insumos a Nueva Orleans. Las confrontaciones entre kaskaskias y peorías contra chicachas y quiraves provocaban que los primeros solicitaran protección de los arkansas o quapaws y que la comandancia del fuerte se viese obligada a mantenerlos por la falta de víveres. ${ }^{42}$ El objetivo de las autoridades era hacer perdurar la armonía dentro de los puestos fronterizos y la paz entre los indígenas; era una cuestión tanto económica como estratégica, como indica González López-Briones: un escaso número de europeos rivales hacían necesaria «la ayuda de los indios para controlar los territorios» ${ }^{43}$ igualmente procuraban evitar los abusos que los comerciantes y los tramperos cometían contra los indios. ${ }^{44}$

Franceses y británicos llevaban décadas explotando el comercio de pieles, uno de los negocios más rentables en este periodo. Se trataba, además, de un artefacto diplomático. Como señala Richard White: «fur trade proper is merely an arbitrary selection from a fuller and quite coherent spectrum of exchange that was embedded in particular social relations»; ${ }^{45}$ la documentación explicita, efectivamente, que conllevaba la salida de otros productos: «cambalachando con inmensas ganancias géneros bastos, aguardientes, chucherías, pólvora, y balas, tras sus peleterías». ${ }^{46} \mathrm{La}$ introducción de las pieles en el mundo europeo aportó importantes beneficios a empresas inglesas, como la de Panton, Leslie y Compañía, y posibilitó las relaciones con los nativos, hasta el punto de que muchos de sus agentes se instalaban en las poblaciones, «cohabitando con las doncellas» hasta granjearse «la voluntad de todos». ${ }^{47}$ Beneficios a particulares y a la nación, que derrochaba «thesoros en regalar y agasajarlos por el conducto de sus Governadores, y Superintendentes» para ganarse el beneplácito de los indígenas. ${ }^{48}$ Con la modificación de la frontera norteamericana tras la independencia y la libre

42 José Orieta, comandante del puesto de Arkansas, al gobernador de la Luisiana, 4 de junio de 1770, AGI, Papeles de Cuba, 107, f. 66v.

43 González López-Briones, 1995, 121.

44 Véase Capitán general a Demazellieres, 13 de septiembre de 1770, AGI, Papeles de Cuba, 107, f. 128

45 White, 2011, 94.

46 «Discurso preliminar sobre indios del gobernador de San Agustín», 16 de noviembre de 1786, en Expediente relativo al surtimiento de géneros para los indios de La Luisiana y La Florida, Archivo Histórico Nacional, Madrid (AHN), Estado, 3885bis, exp. 8, n. 21, f. 1v. Disponible en http:// pares.mcu.es/ParesBusquedas20/catalogo/show/12692274?nm [Consultado: 13/11/2019].

47 Ibidem.

48 Ibidem, f. 2 r. 
circulación por el Misisipi, los ingleses siguieron pululando por el golfo de México y manteniendo alianzas con algunos jefes indios. ${ }^{49}$

Estos precedentes llevaron a las autoridades españolas a no «dudar de lo interesante que es el Comercio con los Yndios en la amistad, y ventajas que asegura». ${ }^{50}$ Pero la realidad del negocio de las pieles era bien distinta y ponía en apuros a los españoles, que recibían quejas diarias de los indígenas que llevaban su mercancía al puerto de Mobile - también Mobila o Movila en la documentación, en la actual Alabama-, donde la intercambiaban o vendían para comprar artículos variados, más caros cada año, mientras que sus pieles se devaluaban. Para remediarlo, la administración colonial tuvo que pactar un valor fijo porque, según los españoles, chactas, chicachas, alibamones, talapuches o creeks no comprendían las leyes de la oferta y la demanda de los mercados de Londres y París, en definitiva «las vicisitudes del comercio». ${ }^{51} \mathrm{El}$ predecesor de Carondelet, el reusense Esteban Rodríguez Miró, ${ }^{52}$ expuso la situación de monopolio a la que se sometía a los indios y que estos amenazaban con romper, buscando tratos con un mercader de un brazo del río Misisipi. El gobernador ilustraba la situación recogiendo las palabras del jefe chacta, Franchimastabé:

Los blancos por el recurso del dinero hallan siempre medio de hacer su comercio, pero los pobres hombres colorados no tienen otros recursos que la peletería, que es bien de dolor para ellos ver que los tratantes no quieren tomar las pieles al precio de la tarifa

49 Es representativo el caso del aventurero inglés William Bowles, sobre quien volveremos más adelante. Véase: «Declaración que hace Guillermo Cunninghan en atención al robo hecho en los Almacenes de don Guillermo Panton», 16 de enero de 1792, en Intentos E.E. U.U. (sic) atacar Louisiana, Archivo General de Simancas, Valladolid, Secretaría de Estado y del Despacho de Guerra, leg. 7244, n. 425. Disponible en http://pares.mcu.es/ParesBusquedas20/catalogo/show/1308563?nm [Consultado: 26/11/2019].

50 Expediente relativo al surtimiento de géneros para los indios de La Luisiana y La Florida, AHN, Estado, 3885bis, exp. 8, 19 de septiembre de 1788, ff. 78-79.

51 Dos conferencias en la nación chacta, en las que concurrió el principal jefe chicacha en presencia de Guillermo Davenport, comisario enviado por el estado de Georgia para atraerse la amistad y comercio de las expresadas naciones, enviadas a José de Gálvez, marqués de Sonora, firmadas por Esteban Miró, 1 de junio de 1787, AGI, Papeles de Cuba, 1394, ff. 12-15. Las naciones chactas, chicachas (o choctaws y chickasaws) y alibamones se asentaban entre la Florida occidental y Luisiana, mientras que talapuches (o tallapoosas, división de los indios creek) habitaban al norte de Florida, en frontera con la actual Georgia.

52 Esteban Rodríguez Miró y Sabater (1744-1795), o simplemente Esteban Miró, fue uno de los gobernadores más populares de la Luisiana española, de 1785 a 1791, a donde había llegado como militar con Bernardo de Gálvez. Fue muy reconocido por sus decisiones para afrontar el gran incendio de Nueva Orleans, de 1788. Le sustituye Francisco Luis Héctor, barón de Carondelet (1748-1807), que ocupa el cargo de 1791 a 1797; además de modernizar la capital, durante su gobierno se estrecharon las relaciones con las naciones indias de la zona. 
hecha en el congreso por el desecho que experimentan de las pieles y cree que es para hacer los hombres colorados pobres..$^{53}$

Sin embargo, la situación del mercado de pieles soportaba una oferta creciente, sobre todo por los tramperos de Kentucky, que viajaban al almacén de Nueva Orleans para vender comestibles, como barriles de harina, galones de whisky y tocino, y también pieles de alta calidad. Tal es el caso de William Garland, que en la primavera de 1801 dejó en calidad de depósito: «315 barriles de harina, 1.700 pesos, 183 pieles de venado, 23 pieles de castor, 40 pieles de gamo y 6 pieles de oso», o el de Henry Stagg que entregó « 27 pieles de venado, 6 de oso, 250 de gato montés y 9 de nutria». ${ }^{54}$

\section{Del gobierno de los sujetos fronterizos: el indio como cuerpo útil}

La dinastía borbónica marcó una nueva era de la Corona española, que intentó prolongar su acción renovadora en todos sus territorios. Con base en el racionalismo y la Ilustración y un pie en el Antiguo Régimen, se fue desarrollando una conciencia social basada en el deber de los individuos hacia la monarquía, encargada del bien común y de garantizar los derechos de sus súbditos. Según Elliott, el reformismo borbónico se proyectó en América como medio de relanzar su imperio con una denodada pasión comercial:

Los proyectos de reforma asociados al nombre de Gálvez, que implicaban innovaciones fiscales, administrativas y comerciales a una escala sin precedentes, son un testimonio del alcance de la transformación de las actitudes y de los supuestos previos acerca del imperio español de las Indias que habían ido cobrando fuerza en Madrid en el transcurso de las décadas centrales del siglo XVIII. ${ }^{55}$

Los nuevos sistemas de subordinación requerían vigilar al individuo para evitar el resquebrajamiento del orden. Esta función policial implantó una nueva praxis en la relación de poder, donde gobernar, como aclara Foucault, «designaba el modo de dirigir la conducta de individuos o grupos»; más allá

53 Franchimastabé a Miro, firmada en el Yasú, 19 de marzo de 1797, AGI, Papeles de Cuba, 1394, ff. 12-15 y 14v y 15r. Franchimastabé fue uno de los principales líderes chactas en las tres últimas décadas del siglo XVIII, tejió sólidos contactos comerciales y alianzas con las sucesivas potencias europeas que dominaron la zona y con sus vecinos estadounidenses.

54 Libros de registro del Guarda Almacén de Nueva Orleans, 1798-1803, AGI, Papeles de Cuba, 631, f. 178v. Los mejores meses para la captura de animales eran los de primavera y verano; el deshielo también favorecía el descenso de las canoas y las piraguas hasta Nueva Orleans.

55 Elliott, 2006, 448. Se refiere a José de Gálvez y Gallardo, secretario de Indias de 1775 a 1787 y tío de Bernardo de Gálvez. 
de la sujeción económica o política, el gobierno controlaba modos de acción «destinados a actuar sobre las posibilidades de acción de otros individuos». ${ }^{56}$ Tener a su favor a las naciones indias fronterizas era clave para que España impusiera su superioridad. Y, sin llegar a supeditar estas etnias a un férreo colonialismo, se procuró actuar sobre su «corpus social», modelar pautas de comportamiento e instrumentalizar el regalo como modo de filiación.

Como se desprende de la documentación, el indígena era un sujeto útil para la Corona contra la influencia creciente de sus competidores. En una carta de Las Casas al conde de Aranda, el gobernador exponía la idea de «formar una alianza general de todas las Naciones Indias interpuestas entre las posesiones del Rey y las de los Estados Unidos, atraerlas, y conservarlas a nuestro partido, inspirarlas oposición a ceder tierras a los Americanos a fin de contenerlos en limites mas lexanos de los nuestros». ${ }^{57}$ Para lograrlo era preciso seguirles de cerca a través de la figura del comisario residente, denominación que describe a estos agentes y militares conocedores del territorio y hablantes de varias lenguas, que representaban al gobernador ante las naciones indias, con las que compartían sus tradiciones y ceremonias, ${ }^{58}$ su misión era muy delicada pues entrañaba un fuerte compromiso con el pueblo que los acogía - algunos incluso se integraban en las familias de los jefes-, pero también debía vigilar sus pasos y «desvanecer todas las intrigas» contrarias a los intereses españoles y desmentir las «falsedades que esparcen en aquellas Naciones» los angloamericanos. ${ }^{59}$ Con el tiempo, se convertiría en el «xefe de todos los blancos» que residieran en los asentamientos indios. ${ }^{60}$

56 Foucault, 1988, 10-15.

57 Las Casas a Carondelet, en Gobernador de la Habana sobre reedificación de dos fuertes, 3 de diciembre de 1792, AGI, Estado, 9, n. 27, f. 1r-1v. Disponible en http://pares.mcu.es/ParesBusquedas20/ catalogo/show/62038?nm [Consultado: 15/10/2019].

58 Proponemos utilizar este término que explica muy bien lo que significaron agentes como José Orieta, Luis Milfort, Pedro Olivier o Juan de la Villebeuvre, algunos de estos comisarios residentes asumieron una función primordial en la diplomacia borbónica. De este último, por ejemplo, Holmes (1980, 389) subraya: «Virtually the whole story of Spanish success with the Choctaws is interrelated with his career in Louisiana and West Florida».

59 Carondelet al conde de Aranda, 25 de julio de 1792, en «Cartas del barón de Carondelet, gobernador intendente de la Luisiana y Florida occidental, a la Secretaría de Estado, con otros documentos relativos a la cesión de los Nogales y diversas tribus indias», AHN, Estado, 3898, exp. 5, f. 4v. Disponible en http://pares.mcu.es/ParesBusquedas20/catalogo/show/12692029?nm [Consultado: 26/10/2019].

60 «Memorial de don Manuel Gayoso de Lemos sobre los indios y el tratado firmado», 6 de diciembre de 1793, en «Cartas del barón de Carondelet, gobernador intendente de la Luisiana y Florida occidental, al duque de la Alcudia, con otros documentos sobre la navegación del Mississippi», AHN, Estado, 3899, exp. 1, f. 11r. Disponible en http://pares.mcu.es/ParesBusquedas20/catalogo/ show/12692088?nm [Consultado: 04/11/2019]. 


\section{FIGURA 3}

«RELACIÓN Y ESTADO DEL REGALO PENDIENTE QUE DEBE ESTAR PRONTO

EN ESTA PLAZA A LA DISPOSICIÓN DE LOS XEFES

QUE ABAXO SE EXPRESAN» (1792)

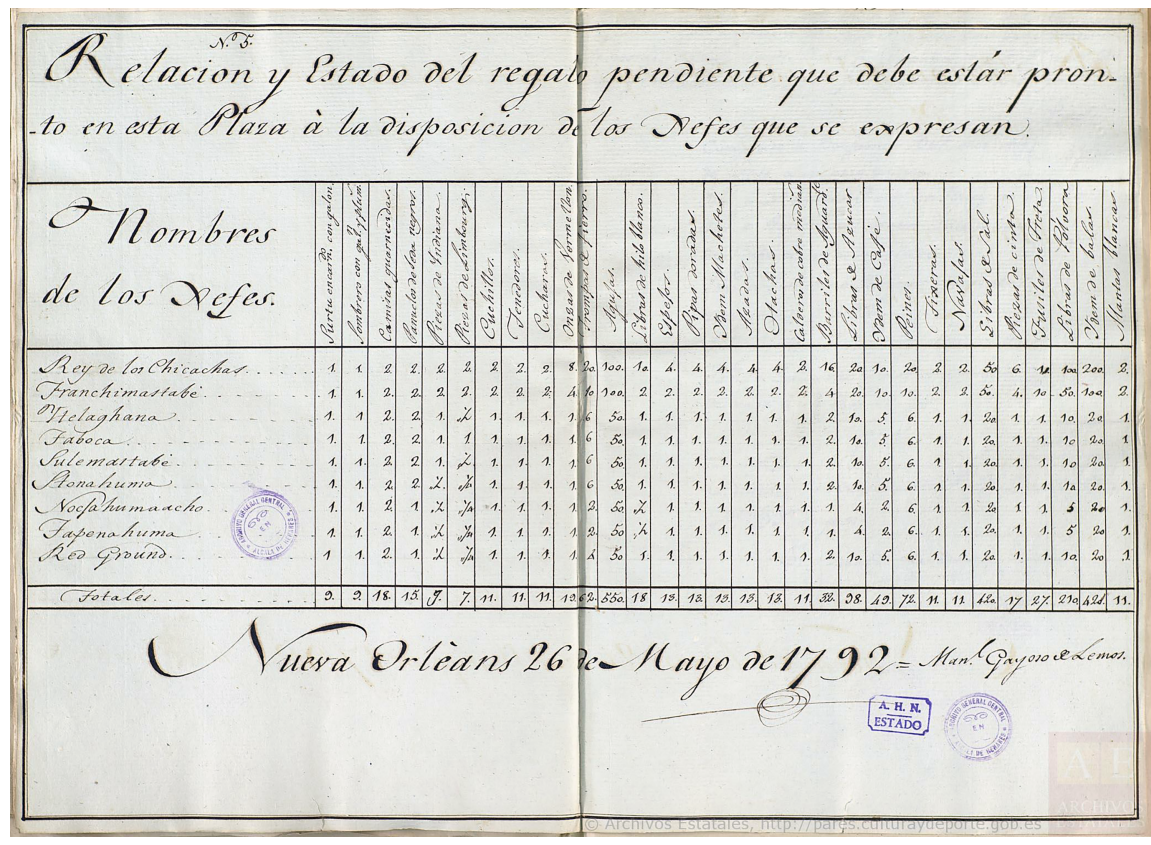

Fuente: Manuel Gayoso de Lemos al Barón de Carondelet, en «Cartas del barón de Carondelet, Gobernador Intendente de la Luisiana y Florida occidental, a la Secretaría de Estado, con otros documentos relativos a la cesión de los Nogales y a diversas tribus indias». España, Ministerio de Cultura y Deporte, Archivo Histórico Nacional, Estado, 3898, exp. 5.

La Corona puso especial cuidado en evitar en sus tierras el establecimiento de colonos «de nación alguna que sean blancos» sin permiso de las autoridades. En el verano de 1774, José Orieta, jefe del puesto de Arkansas, relataba al gobernador de Luisiana, Luis de Unzaga, la convocatoria de una junta con los jefes para que «se deshicieran de los ingleses que hallaban en sus pueblos casados con indias», quienes, en caso de retornar, serían apresados; los colonos intoxicaban a los indios con rumores sobre la propiedad de las tierras, que «no eran de nuestro monarca» como evidenciaban el pésimo estado de la empalizada del fuerte y el deplorable mantenimiento de la guarnición, y obligaban al comandante del puesto a alardear de la buena 
situación del destacamento con descargas de artillería y a organizar visitas al recinto para convencerles «de que el inglés les tenía engañados». ${ }^{61} \mathrm{Al}$ margen de querer manipular a los jefes indios, la realidad se correspondía con la descrita: las condiciones de los fuertes eran lamentables. El de Arkansas se inundaba constantemente y el resto de las guarniciones necesitaban reparaciones diarias debido a las abundantes lluvias, crecidas de los ríos y a los huracanes.

\section{El regalo como instrumento para atraer la voluntad del sujeto}

Las connotaciones derivadas de un territorio tan fluctuante conllevaron un reajuste en la política borbónica, que tuvo que poner en práctica todas sus habilidades diplomáticas. Frente a la amenaza de los americanos, las autoridades diseñaron una estrategia de buen entendimiento y alianza con los indígenas para que permanecieran afines a su causa; la idea era «pacificar a los indios con el fin de desarrollar las regiones fronterizas», como señala David Weber. ${ }^{62}$ Las órdenes expedidas por la metrópoli sugerían un protocolo de buena vecindad y es aquí donde el regalo representó un papel esencial con el que generar vínculos que les permitieran influir en ciertas actitudes indígenas y reconducirlas a sus intereses. La correspondencia revela que las autoridades conocían bien que el regalo era una herramienta relacional tan asentada entre las naciones del sureste americano que debían conservarla para asegurar una convivencia duradera con las naciones indias. Las mercancías habituales eran fusiles, pólvora, balas, piedras de chispa, aguardiente de caña, sal, espejos, hachas, cadenas, bermellón, sal, panes, harina, café, azadas, sombreros, camisas o piezas de limburg, un tejido muy apreciado para tejer casacas, y quincallería y abalorios de todo tipo. ${ }^{63}$

Los nativos se habían ganado el respeto y el temor de los españoles, no solo por su comportamiento impredecible y a veces hostil, sino porque Estados Unidos los consideraba naciones con capacidad negociadora y comercial, lo que podría ser contraproducente. A su vez, la cordialidad con los indígenas era primordial por las dificultades que entrañaba cuidar

61 Todas las citas del párrafo en José Orieta al capitán general Luis de Unzaga, 6 de junio de 1774 y 14 de julio de 1774, AGI, Papeles de Cuba, 107, ff. 190-194.

62 Weber, 2007, 213.

63 «Relación de Tomás Portell, comandante del puesto de Nuevo Madrid, de los efectos que han recibido pertenecientes al ramo de indios», 1 de enero-31 de diciembre de 1795, AGI, Papeles de Cuba, 546, ff. 260r-261v. 
de los enclaves fronterizos. Quedaba claro, por tanto, la necesidad de pactar con ellos. Las naciones indias eran apreciadas por comportarse como quintacolumnistas en zonas ocupadas por los estadounidenses, valoradas por su número, capacidad de maniobra y de convocatoria, por sus técnicas de ataque y por su conocimiento del terreno, cualidades muy valiosas ante una hipotética guerra con Estados Unidos. La Corona no se podía permitir añadir un enemigo más a la larga lista de pretendientes territoriales, por lo que es reseñable la consideración diplomática en la que eran tenidos estos grupos como potenciales aliados de los enemigos de España.

Si comparamos la experiencia con las poblaciones amerindias mesoamericanas y andinas, tenidas como altas culturas y tratadas en el discurso historiográfico colonial como imperios, y cómo, a pesar de ello, fueron sometidas a un régimen de compulsión laboral sin precedentes, sorprende el trato concedido a estos grupos indígenas del Norte, que a menudo se estructuraban en sociedades de bandas y a los que se solía calificar de salvajes, bárbaros e incivilizados en la documentación institucional. ${ }^{64}$ Sin embargo, el gobierno español no desplegó una política represiva, de concentración o de evangelización, sino todo lo contrario, la cercanía de un enemigo tan imponente como la nueva nación americana invitó a reflexionar sobre la función que estos indios podían jugar en su estrategia fronteriza, un planteamiento que ejemplifica la adaptabilidad del estado ante un escenario inédito y los antes bárbaros, sostiene Weber, pasaron a ser «individuos comerciales por naturaleza, dispuestos a dejarse apaciguar mediante regalos y mercancías». ${ }^{65}$

La ayuda con armas y municiones a los indios era el patrón de actuación más habitual, ya que, según los españoles, «no podemos dexar de hacer, sin exponer esta Provincia [La Luisiana] a ser invadida en los años sucesivos». ${ }^{66}$ Es conveniente precisar que las entregas de víveres y armas se disfrazaban bajo la credencial de regalos para «despreocupar con este título cualquier celo o resentimiento de los americanos». ${ }^{67}$ Con esta argucia verbal se evitaban acusaciones de colaboracionismo y tensiones

64 Sobre el concepto del salvaje, véase Álvarez Cuartero y Baena Zapatero, 2021.

65 Weber, 2007, 271.

66 Carondelet a Luis de las Casas, 22 de marzo de 1792, en «Cartas del barón de Carondelet, gobernador intendente de la Luisiana y Florida occidental, a la Secretaría de Estado, con otros documentos relativos a la cesión de los Nogales y diversas tribus indias», AHN, Estado, 3898, exp. 5, n. 24 , f. 2 r.

67 Declaraciones hechas en la plaza de Panzacola [Pensacola], agosto de 1788, AGI, Papeles de Cuba, 1394, f. 92v. 
diplomáticas no deseadas, si bien la compra de voluntades mediante regalos era sobradamente conocida por todos. En las disputas entre americanos y talapuches, estos solicitaron rifles a los españoles «no solo para la guerra sino para la caza» y, aunque les proporcionaron la ayuda reclamada, recalcaron su neutralidad con manifestaciones ambiguas: «no somos nosotros quienes les indujimos a esta guerra que ellos han emprendido a causa de las usurpaciones que dicen les han hecho los americanos y que por lo tanto deben no abusar de nuestra proteccion». ${ }^{68}$ La política aconsejada para la zona era defensiva. Gardoqui, uno de los más competentes negociadores de la época, recomendaba que no se atacase y que se auxiliara a los indios si llegaban a ser hostigados por el enemigo. El embajador fue tajante al respecto: «no ataquen a los americanos y se mantengan en la defensiva pues en el caso de ser invadidos se les sostendrá como corresponde». ${ }^{69}$

Para Franchimastabé, jefe de los chactas, no había que sorprenderse «de ver muchos blancos sobre mi tierra, estos blancos no son perros, se les debe escuchar y no hablar en cólera»..$^{70}$ De estas palabras se deduce que los indios trataban de tú a tú a los extranjeros, fruto de las interacciones surgidas a lo largo del siglo. Uno de los puntos de encuentro más eficaces fue el comercio, que Weber considera eje articulador de la paz gracias a los vínculos que se crearon para normalizar las transacciones. ${ }^{71}$ En su estudio sobre el don, Mauss concluía que las sociedades «han progresado en la medida en que ellas mismas, sus subgrupos y [...] sus individuos, han sabido estabilizar sus relaciones, dar, recibir y, por último, devolver», han moderado los contactos violentos y han aprendido a «intercambiar bienes y personas, $[\ldots]$ a crearse intereses, a satisfacerlos mutuamente y $[\ldots]$ a defenderlos sin tener que recurrir a las armas» ${ }^{72}$ La adaptabilidad de los españoles al medio fue vital para consolidar sus planes; en general, podría afirmarse que adoptaron una postura pragmática en sus tratos fronterizos. Lejos de combatir la red comercial que había tejido la casa británica Panton, Leslie y Compañía, por ejemplo, la mantuvieron y se beneficiaron del usufructo de uno y otro lado: la continuidad de una empresa que tenía «la satisfaccion de las Naciones Yndias, evitaba un vacío comercial y no dar

68 Esteban Miró a José de Ezpeleta, capitán general de Cuba, 6 de noviembre de 1787, AGI, Papeles de Cuba, 1394, f. 36.

69 Antonio Valdés, secretario del Consejo de Indias, al gobernador de la Luisiana, 31 de julio de 1787, AGI, Papeles de Cuba, 1394, f. 37.

70 Dos conferencias en la nación chacta, 1 de junio de 1787, AGI, Papeles de Cuba, 1394, f. 16.

71 Véase Weber, 2007, 127.

72 Mauss, 2009 [1925], 257. 
ventaja a los estadounidenses porque «cesando de golpe la introducción de los generos a que están acostumbrado los Yndios, quedaran disgustados, y propensos, es de temer, a prestar sus ohidos, que hasta ahora han tenido cerrados, á las insignuaciones de los Americanos, quienes han procurado y procuran con el mayor empeño atraer su amistad». ${ }^{73}$

El proceso de interacción con los diversos grupos solía comenzar por contactar con los jefes o cabecillas, un hecho crucial que podía resultar conflictivo dependiendo de la aceptación que tuviera el agente enviado. Para sortear este escollo, con la práctica del regalo podían reforzar el poder de los líderes más adeptos frente a sus adversarios e incluso intervenir directamente en su elección; como dice Weber: «es un hecho que las autoridades españolas alteraron las jerarquías [...], sin proponérselo, sembraron el descontento dentro de las sociedades tribales al designar a los líderes indios». ${ }^{74}$ Podemos calificar la situación de clima de temor y desconfianza entre todas las partes.

La posición privilegiada de los británicos les amparó en su intento de interferir en las rutas españolas que unían México con la Comandancia General de las Provincias Internas y seguir comerciando con las diversas etnias. Los indígenas trataban con el mejor postor: si los españoles suspendían los suministros o los vendían en peores condiciones económicas, acudían a los británicos o a los estadounidenses. Era una cuestión de supervivencia. En la batalla por franquear el monopolio comercial es interesante comentar el incidente que protagonizó el aventurero y tejedor de intrigas William August Bowles. ${ }^{75}$ Junto a un grupo de indios de varias tribus, atacó

73 «Discurso preliminar sobre indios del gobernador de San Agustín», 16 de noviembre de 1786, en Expediente relativo al surtimiento de géneros para los indios de La Luisiana y La Florida, AHN, Estado, 3885bis, exp. 8, n. 21, f. 3v. Vicente Manuel de Céspedes, gobernador de Florida Occidental (1784-1790), consideraba necesario continuar tratando con la empresa británica por su gran implantación e influencia entre las naciones indígenas; de esta forma, la empresa británica perpetuó su monopolio comercial bajo el dominio español.

74 Weber, 2007, 313.

75 William Augustus Bowles (1763-1805), británico asimilado a los creek y conocido como Estajoca. Se desenvolvió entre el comercio y la política y conspiró para organizar un estado indígena independiente de las tres potencias; lo logró por un corto espacio de tiempo, en 1796, junto con los semínolas, al nordeste de Florida, y fue conocido como Estado de Muskogee. Véanse los documentos: Barón de Carondelet al conde de Aranda sobre el aventurero Guillermo Augusto Bowles, 31 de julio de 1792, en «Cartas del barón de Carondelet, gobernador intendente de la Luisiana y Florida occidental, a la Secretaría de Estado, con otros documentos relativos a la cesión de los Nogales y diversas tribus indias», AHN, Estado, 3898, exp. 5, n. 9, f. 1r-1v; y Gobernador de las provincias de Luisiana y Florida occidental con copia de carta del comerciante Guillermo Panton y documentación relativa a los asuntos de Bowles y a la ayuda prestada por el Lord Dunmore, 10 de septiembre de 1792, en ibidem, n. 13, ff. 1-16. 
los almacenes de Panton, Leslie y Compañía, cercanos al fuerte San Marcos de Apalache, y se apropió de víveres, armas y municiones con el objetivo de hacerse con las redes clientelares indígenas del Misisipi. De acuerdo con la documentación, sin embargo, las intenciones de Bowles irían a provocar un nuevo conflicto hispano-británico: «si los españoles me dan motivo para obrar contra ellos, no hesitaré un momento, pero quiero que ellos sean los agresores, hallándome determinado a no comenzar con ellos y si a provocarlos para que empiecen conmigo». ${ }^{76}$ De cualquier forma, el mayor competidor en liza era la ambiciosa nación vecina, que tenía sobradas razones para irrumpir en el negocio con los indígenas y sabía que era necesario «cultivar su amistad por medio de enlaces mercantiles, y algunos regalos». ${ }^{77}$

A finales de siglo la «guerra de relaciones» se había desatado. Los indígenas no solían arriesgar en sus amistades, como muestra el informe de Juan de la Villebeuvre sobre la visita a Cumberland de 550 chicachas y 107 chactas para negociar con William Blount, gobernador estadounidense para el Suroeste, el establecimiento de una factoría en Bear Creek, un proyecto que no les convencía porque, si se asentaba «en aquel parage, no podría sostenerse en él pues que los talapuches los mataban hasta en sus aldeas» ${ }^{78}$. De todas formas, Ugulayacabé Mingo — «Amigo de los Lobos», jefe chicacha Gran Medalla - aseguró a Blount que no tomarían partido por ninguna fuerza en caso de guerra entre hombres blancos. ${ }^{79}$ Es decir, la conducta de los indios variaba en función de sus intereses, su amistad tenía precio y la daban o no según la cuantía y beneficios de la recompensa.

Los españoles lograron contar a veces con la amistad segura de algunos indios valiéndose, sobre todo, de los comisarios residentes que congeniaban con las etnias mientras impedían que se resquebrajara el orden social. Juan de la Villebeuvre, por ejemplo, recurrió a talapuches amigos para que avisaran a los chactas de «no dexarse engañar por los Americanos, quienes no intentan otra cosa que apoderarse de sus tierras, y hacer esclavos sus Mugeres, e hijos, como han hecho con los cheraquies». ${ }^{80} \mathrm{Y}$ en

76 Guillermo Augusto Bowles a Jayme Burgets, 7 de febrero de 1792, en ibidem, n. 9, f. 2r.

77 «Traducción en resumen de un librito inglés que contiene un extracto de los apuntes de la Compañía de la Carolina del Sur en el Yazú, Impreso en Charleston en el año de 1791», Carta n. 9, 25 de febrero de 1792, en ibidem, f. 8 r.

78 Juan de la Villebeuvre al barón de Carondelet, 12 de septiembre de 1792, en ibidem, n. 14 , f. 1 r.

79 Barón de Carondelet al conde de Aranda, 8 de noviembre de 1792, en ibidem, n. 20, f. 2r-2v.

80 Juan de la Villebeuvre al barón de Carondelet, 12 de septiembre de 1792, en ibidem, n. 14, ff. $3 v-4 r$. 
una conferencia de William Blount con los jefes cheroquis Little Turkey, Bloody Fellow y otros principales, se les preguntó «si amaban, y estimaban a los Españoles, a que respondieron que sí», y el motivo que dieron fue «que los Españoles jamas les pedían nada, y si algo les daban era meramente por benevolencia grata». ${ }^{81}$ La hipocresía y el rumor, sin embargo, eran comunes entre españoles y nativos. En 1770, el jefe Perruquier, portavoz de los aufaubulas — tal vez affagoula—, había divulgado entre sus vecinos una serie de infamias argumentando que, si «los chactas venían a atacarlos, nadie tendría la culpa sino los españoles y franceses», por lo que Pedro Piernas, teniente de gobernador en la Alta Luisiana (1770-1775), «mando juntar a los jefes y les hizo varias reconvenciones sobre esos rumores asegurandoles despues que siempre la nacion española los miraria con cariño y que si se comportaban bien tendrían anualmente los mismos regalos que les habia dado y que no debian dar credito a nada sino a lo que les decian los jefes». ${ }^{82}$

Aceptar el regalo conllevaba una serie de condiciones que los caciques tenían que hacer cumplir a los suyos: «los ponen en obligación de que ellos induzcan a los indios de sus naciones que reconociendo este beneficio se porten con los españoles y demas vasallos habitantes de esta colonia con paz, tranquilidad y buena armonia». ${ }^{83}$ En el curso de las transacciones, la valía de los regalos entregados podía ser cuestionada por los indios, que se quejaban de la mala calidad del género, como sucedió con los cañones de unos fusiles que reventaban al ser disparados. ${ }^{84}$ Las represalias ocurrían cuando el regalo no era de su agrado o no se correspondía con lo pactado, así en 1788 dos jefes alibamones de la aldea Taskiky mataron «dos bueyes del rey» por «no haberles dado el regalo que pedían». ${ }^{85}$ Es importante señalar que los españoles confiaban plenamente en la transcendencia que los

81 «Oficio reservado n. ${ }^{\circ} 154$ del gobernador de la Luisiana al Capitán General», 31 de diciembre de 1795, en Gobernador Habana remite varios documentos, AGI, Estado, 5A, n. 55, f. 7r. Disponible en http://pares.mcu.es/ParesBusquedas20/catalogo/show/61855?nm [Consultado: 05/10/2019].

82 Francisco Demazellieres al gobernador de la Luisiana, 15 de mayo de 1770, AGI, Papeles de Cuba, 107, f. 61v.

83 Capitán General a Demazellieres, 13 de septiembre de 1770, AGI, Papeles de Cuba, 107, f. $128 \mathrm{r}-128 \mathrm{v}$.

84 «Los indios recibieron el año pasado de mala gana la polvora y fusiles, tengo entendido se hallan en animo de no tomarlos este año si no se les envían ambos generos de mayor calidad; de los fusiles puedo asegurar a VS (pues muchos los han venido a enseñar) que cuantos recibieron en el presente se les han reventado, sin que haya podido componerse ni uno» en «Fernando de Leyva, comandante del puesto de Arkansas, al capitán general Unzaga», 2 de enero de 1772, AGI, Papeles de Cuba, 107, f. 278r.

85 Vicente Folch a Miró, Mobila, 14 de agosto de 1788, AGI, Papeles de Cuba, 52, ff. 273 y 274. 
regalos alcanzaban en estas poblaciones, donde ayudaban a soslayar situaciones espinosas que debían ser miradas con cautela y cierta preocupación; así se vislumbra en una carta del comandante del puesto de Arkansas:

[L]os Arkansas, los habitantes y tropa estan tranquilos y sosegados, y VM solo es el que esta inquieto por rumores que no merecen la menor atencion como lo acredita la experiencia, además este VM segurisimo que la buena conducta del oficial que esta ahi mandando, su esmero y agrado con esos salvajes a quienes se les da VM tan bello regalo hara siempre mas impresion que las vagas y mal fundados roces ni de los ingleses, ni de los salvajes. ${ }^{86}$

Esta confianza en el poder de persuasión del regalo llevó a las autoridades a asignar un sueldo a indígenas destacados por su carisma, la admiración del resto del grupo y buenas dotes para negociar. Un ejemplo de personaje influyente fue el hacendado y comerciante Alexander McGillivray, líder mestizo de los creek y hábil intermediario con ingleses y españoles, con quien la Corona quería estrechar lazos «por el general buen concepto que tiene adquirido, especialmente entre aquellos naturales, que le respetan extraordinariamente», razón por la que el gobernador Miró estimaba conveniente «asignarle los dos mil pesos que propone, y aun estenderse, si lo hallare por conveniente à doble cantidad, respecto á que este sugeto se halla al mismo tiempo alagado de los Estados Unidos, y de los Yngleses»;87 la sugerencia de Miró motivó palabras de agradecimiento de McGillivray, ya que la gratificación haría «mi situacion mas comoda e independiente que hasta aqui, a cuyo favor correspondere agradecido y obligado en todo evento a la amistad de V.S.». ${ }^{88}$ Dos mil pesos era también la pensión que recibía el general estadounidense James Wilkinson, suerte de agente doble que informaba a los gobernadores españoles sobre los pasos de americanos

86 Francisco Demazellieres al Capitán General, 27 de julio de 1770, AGI, Papeles de Cuba, 107, f. 119 .

87 Carta reservada de Esteban Miró a Luis de las Casas, 25 de diciembre de 1790, en «Gobernador Luisiana sobre el paraje llamado Walnut Hills», AGI, Estado, 9, n. 16, f. 5r. Disponible en http://pares.mcu.es/ParesBusquedas20/catalogo/show/62027?nm [Consultado: 03/10/2019]. Las relaciones de Miró y la Corona con McGillivray se remontan años atrás y su presencia es visible en numerosos actos de acercamiento entre españoles y creeks o talapuches, como en la firma del Tratado de Pensacola (1 de junio de 1784); de hecho, fue el valedor de la compañía Panton para comerciar en Florida y entre las naciones indias del Sudeste; en Caughey, 2007, 75-78. Según Hoffman (1992, 310), «su deseo era echar a los americanos de Georgia, Tennessee, y Kentucky con ayuda de Gran Bretaña o España».

88 Alexander McGillivray a Esteban Miró, 26 de febrero de 1791, en «Gobernador Luisiana sobre el paraje llamado Walnut Hills», AGI, Estado, 9, n. 16, f. 1r. 
y franceses en el área del Misisipi y de los posibles movimientos de expansión de las compañías comerciales hacia el Oeste. ${ }^{89}$

Con la llegada del conde de Carondelet a la provincia de Luisiana, la mediación de Alexander McGillivray y su amistad seguían siendo muy apreciadas para evitar «la guerra con los Estados Unidos, pero manteniendo en él la desconfianza de los Americanos»..$^{90} \mathrm{Al}$ fin y al cabo, estos habían firmado en 1790 un tratado de paz y amistad en Nueva York - conocido como Tratado Muscoghi-, promovido por Henry Knox, ministro de Guerra de George Washington, y el propio McGillivray, junto a varios grupos de indios creek y semínolas. ${ }^{91}$ El nuevo gobernador debía afrontar otro problema: la erección de un fuerte en el paraje de Nogales —Walnut Hills para los británicos, hoy Vicksburg-, en la confluencia del río Yazú con el Misisipi, amenazaba la convivencia con chactas y chicachas y encontró la oposición de líderes como Franchimastabé. ${ }^{92}$ Para salvaguardar los intereses indígenas y de los propios españoles, Carondelet ordenó a Manuel Gayoso de Lemos, gobernador del distrito de Natchez, ${ }^{93}$ que asegurara su respaldo a la nación chacta, pues el único medio de conservar su territorio era «concluir baxo el amparo de la España una alianza defensiva entre los Chactas, Chicasaws, Creeks, Cheraquies y Chauanones ${ }^{94}$ e impedir que los americanos se introduzcan en sus tierras, en las cuales destruyen toda la

89 Véase Carondelet al conde de Floridablanca, 16 de febrero de 1792, en «Cartas del barón de Carondelet, gobernador intendente de la Luisiana y Florida occidental, a la Secretaría de Estado, con otros documentos relativos a la cesión de los Nogales y diversas tribus indias», AHN, Estado, 3898, exp. 5, n. 7, f. 3r. Tras la Guerra de Secesión, James Wilkinson (1757-1825) fue brigadier general en la milicia de Pensilvania y congresista; sospechoso de traición a su país, conspiró a favor de la anexión del estado de Kentucky a la Corona española, que por unos años cedió a los kentuckianos el control del comercio en el Misisipi.

90 Ibidem, f. $4 \mathrm{v}$.

91 Aunque se firmaba el cese de hostilidades, el tratado significó la cesión de buena parte de las tierras de caza de la nación creek y el compromiso de reconducir su forma de vida hacia la agricultura y el pastoreo, modos más «civilizados» que su actividad de cazadores. Véase «Treaty with the Creeks, August 7, 1790», en Kappler, 1904, 25-29; en particular los artículos IV y XII. Disponible en Edmon Low Library, Oklahoma State University, Estados Unidos, https://dc.library.okstate.edu/ digital/collection/kapplers [Consultado: 14/10/2019].

92 Sobre Nogales, véase Weeks, 2005, 63-80.

93 Gayoso de Lemos (1747-1799) ocupaba el gobierno civil y militar de Natchez desde 1787; sucedió a Carondelet en el gobierno de Nueva Orleans en 1797, hasta su muerte por fiebre amarilla. Promovió sucesivas alianzas (1792, 1793 y 1795) con chactas y chicachas para establecerse en Nogales y en San Fernando de las Barrancas, actual Memphis, puestos que facilitaban el dominio del Misisipi. Natchez era un punto estratégico y de control sobre el río, y un lugar que frecuentaban las naciones de indios vecinas, véase Armillas Vicente, 1977, 86-87.

94 Probablemente, chawashas. 
caza». ${ }^{95} \mathrm{El}$ discurso español, teñido de paternalismo, ratificaba la autonomía de los territorios indígenas bajo la protección de «Su Majestad Católica» en contraposición a los americanos, que habían usurpado tierras a los cheroquis y dado muerte a sus mujeres e hijos. ${ }^{96}$ Con esta estrategia, Carondelet perseguía evitar enfrentamientos y apuntalar la unión de las naciones indias amigas, que podrían vivir en paz en buenos terrenos de caza, haciendo prosperar su comercio y, en suma, servir de escudo contra las actitudes expansionistas de los rivales yanquis.

El trabajo de Gayoso de Lemos concluyó positivamente con la firma de un tratado de amistad con chactas y chicachas por el que cedían a España «todos sus derechos al territorio de los Nogales». Como correspondía a un gesto tan amistoso, la reciprocidad del regalo debía ser de la misma magnitud: por una vez, no se fija una cuantía firme, sencillamente el gobernador Gayoso les entrega «las llaves de estos reales almacenes en que están los efectos para que tomen de ellos lo que quieran hasta satisfacerse». ${ }^{97}$

La compra de voluntades, sin embargo, no siempre repercutió de forma positiva. Respecto a McGillivray, por ejemplo, Carondelet, siguiendo a su antecesor, proponía aumentar su pensión hasta igualar «todo el valor de la que le tienen señalado los Estados Unidos» para atajar sus proyectos con ellos. ${ }^{98}$ Encomendó al teniente Pedro Olivier, comisario del Rey, que lo vigilara — como invitado en su casa de Little Tallassie - y utilizar su influencia para acercarse a otros líderes creek; su misión era ganarse «la confianza de la Nacion, y luego despues desacreditar a McGillivray», es decir, minar su carisma por ser un «hombre pusilánime dado al vicio de la embriaguez»; Olivier se convierte en su interlocutor directo, garante del favor real y encargado de «premiar a los Jefes, y Guerreros, que se le demostrasen afectos, dandoles un vale sobre el Gobernador de Panzacola, con

95 Carondelet a Gayoso de Lemos, 29 de marzo 1792, en «Cartas del barón de Carondelet, gobernador intendente de la Luisiana y Florida occidental, a la Secretaría de Estado, con otros documentos relativos a la cesión de los Nogales y diversas tribus indias», AHN, Estado, 3898, exp. 5, n. 17 , f. 2 v.

96 Véase Carondelet a Franchimastabé, 23 de marzo 1792, en ibidem, ff. 1r-2r.

97 «Tratado de amistad entre el Rey de España, representado por Manuel Gayoso de Lemos, y Tascaotuca, rey de la nación Chicacha, y Franchimastabia, principal jefe de la nación Chacta», 14 de mayo de 1792, AHN, Estado, 3889bis. exp. 12, ff. 1v-2r. Disponible en http://pares.mcu.es/ ParesBusquedas20/catalogo/show/12691864?nm [Consultado: 04/11/2019].

98 Carondelet a Pedro de Olivier, 30 de marzo 1792, en «Cartas del barón de Carondelet, gobernador intendente de la Luisiana y Florida occidental, a la Secretaría de Estado, con otros documentos relativos a la cesión de los Nogales y diversas tribus indias, AHN, Estado, 3898, exp. 5, n. 4 , f. 2 r. 
expresion de los géneros, que este les ha de dar, por via de regalo». ${ }^{99} \mathrm{El}$ éxito de su misión fue pleno y Olivier logró desvanecer «en un instante los intentos de McGillivray para empeñar la nación en la cesión de una parte considerable y la más fértil de su territorio». ${ }^{100}$ De tal manera que, en 1792 , McGillivray se vio conminado a refrendar un nuevo convenio de amistad con Carondelet, comprometiéndose, por un lado, a «remover de una vez qualquier obstaculo que pueda embarazar el absoluto, y entero cumplimiento del tratado celebrado por ambas Naciones en Panzacola el año de 1784» y, por otro, rechazar el acuerdo firmado en 1790 con los Estados Unidos, que había causado «disturbios y descontentos entre los diferentes jefes de la nación»; a cambio, el rey legitimaba la propiedad del territorio creek y suministraría «amplia y suficientemente a sus Indios, y aliados, armas y municiones no solo para defender su país, sino también para recuperar las tierras usurpadas». ${ }^{101}$ Este reforzamiento de la amistad con la nación creek amparaba notablemente los intereses españoles, que volvían a subyugar los de sus rivales americanos.

Sin embargo, las dobles intenciones de McGillivray y la corrompida institución del regalo siguieron proporcionando a los americanos oportunidades para alterar las relaciones hispano-indígenas. El comercio clandestino en el Misisipi, los establecimientos que pretendían abrir los estadounidenses y las diferencias entre chicachas y creeks agujereaban el antemuro que los españoles con tanto ahínco deseaban materializar. Por ello, en octubre de 1793, Gayoso de Lemos congregó en Nogales a representantes de las naciones Chicacha, Creek, Talapuche y Alibamon, Cherokee y Chacta - por este orden en el documento- para sellar un tratado que revalidaba los diversos pactos que se habían formalizado desde $1784 \mathrm{y}$, de gran relevancia, por el que todas prometían «considerar unas a otras como parte de sus propias naciones, de socorrerse recíprocamente y de no determinar punto escencial que pueda influir en la seguridad y conservación de cada una sin consultar a las demás». ${ }^{102}$ La unión indígena beneficiaba a España porque era una baza para alejar a los «Estados Americanos», que tendrían que respetar los acuerdos del tratado y, como contrapartida, las naciones

99 Carondelet al conde de Aranda, 11 de junio de 1792, en ibidem, n. 2, ff. 1v-2r.

100 Ibidem, n. 2, f. 1r.

101 «Tratado de paz y amistad entre España, la nación creek y Alejandro McGillivray», 6 de julio de 1792, en ibidem, ff. 1r-2r.

102 «Tratado de Nogales, 28 de octubre de 1793», AGI, Mapas y planos, Documentos Reales, 7, f. 1r. Disponible en http://pares.mcu.es/ParesBusquedas20/catalogo/show/17800?nm [Consultado: 07/12/2019]. 
conseguían la mediación de Carlos III para garantizar la posesión «pacífica» de sus tierras (arts. 7 y 8). El tratado concertaba, además, la presencia de los comisarios residentes y la entrega anual de regalos a cada grupo, en un lugar de su elección, en vez de lotes más pequeños y frecuentes para hacer más ostentosa la munificencia de los españoles.

A pesar de las buenas intenciones, meses más tarde Luis Milfort, comisario residente en la nación talapuche, denunció la determinación de Estados Unidos de «separar todas las Naciones salvages de la amistad de España á cualquier precio». ${ }^{103}$ Posteriormente, Carondelet informaba al primer ministro Manuel Godoy de que el comisario americano, James Seagrove, había contaminado «a fuerza de regalos gran parte de la Nación Crik; habiendo empeñado algunos guerreros à marchar contra nuestros habitantes inmediatos á San Agustín de la Florida y a cometer alguna muertes en los Chactas, y Chicachas». ${ }^{104}$

Cabe señalar que, además de los regalos, la entrega de medallas era empleada por los españoles para premiar y reconocer la lealtad de los principales jefes indios, solicitándose «de varios tamaños con las armas y busto del rey», así como banderas con la cruz de Borgoña. ${ }^{105}$ El regalo podía ser pecuniario, como los quinientos pesos que se le dieron «reservadamente» al jefe Ugulayacabé, cantidades que también se entregaban a los jefes de alibamones, talapuches y cheroquis designados por el gobernador; incluso se podían recibir adelantos que posteriormente eran descontados del monto total: «y enterado de lo que ha de ir a cada paraje y de la rebaja que ha de hacerse en el regalo de los cherokees de la parte que recibio aquí su jefe poco tiempo hace, he dado las ordenes convenientes al almacen para que todo se disponga con la mayor posible brevedad». ${ }^{106}$

103 Carondelet al duque de la Alcudia, 9 de abril de 1794, en «Cartas del barón de Carondelet, gobernador intendente de la Luisiana y Florida occidental, al duque de la Alcudia, con otros documentos sobre la navegación del Mississippi», AHN, Estado, 3899, exp. 1, n. 31, f. 3v. Jean-Antoine Leclerc de Milfort, también conocido como Louis Milford y como Tastanegy, militar y aventurero francés, era cuñado de McGillivray, quien le nombró comisario de la nación creek. Plenamente asimilado al territorio indio, manifestó su oposición al tratado de Nueva York de 1790, contrario al firmado por creeks y españoles en 1784 .

104 Carondelet al duque de la Alcudia, 1 de mayo de 1794, en ibidem, n. 32, ff. 7v-8r.

105 Carondelet a Luis de las Casas, 2 de diciembre de 1794, AGI, Papeles de Cuba, 152b, f. 668. Véase también el «Oficio n. ${ }^{\circ}$ 288. Contaduría principal del Ejército y Real Hacienda de la Luisiana, dirigido a Enrique Darcantel, intendente del Ejercito y Real Hacienda», 30 de septiembre de 1796, AGI, Papeles de Cuba, 631, f. 112.

106 «Oficio n. ${ }^{\circ} 221$. Contaduría principal del Ejército y Real Hacienda de la Luisiana», 9 de abril de 1796, AGI, Papeles de Cuba, 631, ff. 57v-58r. 


\section{Conclusiones}

La tensión constante entre los diferentes colonizadores, aunada a la tendencia indígena para eludir acuerdos y colaborar a la vez con europeos y estadounidenses, en función de intereses estratégicos, les concedió unos años más de ventaja y, como estima Weber, fortaleció «la capacidad de los indios para mantener su independencia». ${ }^{107} \mathrm{La}$ armonía de las relaciones hispano-indígenas se vio continuamente alterada y la institución del regalo se destinó a comprar la voluntad de los sujetos, lo que encarecía ostensiblemente el coste de los puestos de frontera que, en 1794, se estimaba en unos cien mil pesos anuales. ${ }^{108}$ Por otra parte, Weber sostiene que, en esas mismas fechas, «los obsequios a los indígenas representaban el $10 \%$ de los gastos de España», un presupuesto aceptado con estoicismo porque los funcionarios borbónicos sabían que «la conquista sería más costosa que la paz». ${ }^{109}$

Ni todos los esfuerzos del barón de Carondelet y sus gobernadores ni tantos años de negociaciones y apalabramientos obtuvieron los resultados deseados; su labor se vería opacada en 1795 por la firma del Tratado de San Lorenzo - también llamado Tratado de Madrid y Tratado de Pinckney-, que fijaba la nueva frontera hispanonorteamericana en el paralelo $31^{\circ}$, lo que significó la pérdida de la mayoría de los fuertes — San Fernando de las Barrancas, Nogales o Natchez-, que tanto había costado sostener, y la merma de sus tierras para las naciones indígenas, especialmente los chicachas que, sin la protección de la Corona, terminarían arrinconadas por los colonos americanos. Era el principio de la emergencia hegemónica de Estados Unidos y el declive de la soberanía española en la América del Norte. El gobernador, perspicaz conocedor de estas tierras, se lo había anunciado al rey y al conde de Aranda en 1792, anticipándose a la doctrina del Manifest Destiny: «Ya tengo representado al Rey en oficio reservado n. ${ }^{\circ} 9$ que considero la mencionada concesion como un paliativo del instante, que arrastrará y asegurará indispensablemente y en pocos años la pérdida

107 Weber, 2007, 137. Abelardo Levaggi $(1998,480)$ afirma que las autoridades españolas superaron «en 17.870 pesos a los 40.000 presupuestados para el ramo de Indios».

108 Véase Expediente relativo a la Luisiana y Florida, Carondelet al duque de la Alcudia, 24 de noviembre de 1794, en «Cartas del barón de Carondelet, gobernador intendente de la Luisiana y Florida occidental, al duque de la Alcudia, con otros documentos sobre la navegación del Mississippi», AHN, Estado, 3899, exp. 1, n. 129, f. 8r.

109 Weber, 1998, 160 y 168. 
de estas provincias, y de resultas la del reino de México: el espíritu ambulante, inquieto, é independiente de los americanos no se limitará nunca á la rivera Este del río Misisipi». ${ }^{110}$ Acertó plenamente.

Recibido, 28 de julio de 2020

Segunda versión, 14 de diciembre de 2020

Aceptado, 29 de diciembre de 2020

\section{Referencias bibliográficas}

Álvarez Cuartero, Izaskun y Baena Zapatero, Alberto (eds.), En compañía de salvajes: el sujeto indígena en la construcción del otro, Madrid, IberoamericanaVervuert, 2021 [en prensa].

Armillas Vicente, José Antonio, El Mississippi, frontera de España. España y los Estados Unidos ante el tratado de San Lorenzo, Zaragoza, Institución Fernando el Católico, 1977.

Bolton, Herbert E., The Spanish Borderlands: A Chronicle of Old Florida and the Southwest, New Haven, Yale University Press, 1921.

Caughey, John W., McGillivray of the Creeks, Norman, University of Oklahoma Press, 1938.

Cunha Martins, Rui, El método de la frontera. Radiografía histórica de un dispositivo contemporáneo, Salamanca, Ediciones de la Universidad de Salamanca, 2007.

Elliott, John H., Imperios del mundo Atlántico. España y Gran Bretaña en América (1492-1830), Madrid, Taurus, 2006.

Foucault, Michel, «El sujeto y el poder», Revista Mexicana de Sociología, 50:3, Ciudad de México, 1988, 3-20.

González López-Briones, Carmen, «Noticias sobre los indios quapaws durante el siglo XVIII», Revista Española de Estudios Norteamericanos-REDEN, 7, Alcalá de Henares, 1994, 11-37.

González López-Briones, Carmen, «Reacciones diferentes ante una política similar: los indios osages y los quapaws ante la política comercial franco-española en la Luisiana durante el siglo XVIII», Anales del Museo de América, 3, Madrid, 1995, 119-130.

Hann, John H., A History of the Timucua Indians and Missions, Gainesville, The University Press of Florida, 1996.

Harvey, Sharon R., «Presencing of the Gift and the Economy of Exchange», en Severson, Eric R. (ed.), Gift and Economy: Ethics, Hospitality and the Market, Newcastle, Cambridge Scholars Publishing, 2012, 10-19.

110 Carondelet al conde de Aranda, 7 de julio de 1792, en «Cartas del barón de Carondelet, gobernador intendente de la Luisiana y Florida occidental, a la Secretaría de Estado, con otros documentos relativos a la cesión de los Nogales y diversas tribus indias», AHN, Estado, 3898, exp. 5, f. 1r. 
Hilton, Sylvia, «España y los Estados Unidos en la frontera del Missisipi», en Garrigues, Eduardo y López Vega, Antonio (eds.), España y los Estados Unidos en la era de las independencias, Madrid, Biblioteca Nueva, 2013, 227-236.

Hoffman, Paul E., Luisiana, Madrid, Fundación MAPFRE, 1992.

Hoffman, Paul E., «La situación de los dominios españoles en la América septentrional después de la paz de París en 1783», en Garrigues, Eduardo y López Vega, Antonio (eds.), España y los Estados Unidos en la era de las independencias, Madrid, Biblioteca Nueva, 2013, 201-226.

Holmes, Jack D. C., «La última barrera: La Luisiana y la Nueva España», Historia Mexicana, 10:4, Ciudad de México, 1961, 637-649.

Holmes, Jack D. C., «Juan de la Villebeuvre and Spanish Indian Policy in West Florida, 1784-1797», The Florida Historical Quarterly, 58:4, Orlando, 1980, 387-399.

Jiménez, Alfredo, «La Historia como fabricación del pasado. La frontera del Oeste o American West», Anuario de Estudios Americanos, 58:2, Sevilla, 2001, 733-755.

Jiménez, Alfredo, El Gran Norte de México. Una frontera imperial en la Nueva España 1540-1820, Madrid, Tébar, 2006.

Jones, Oakah L., Los Paisanos: Spanish Settlers on the Northern Frontier of New Spain, Norman, University of Oklahoma Press, 1979.

Juricek, John T., Colonial Georgia and the Creeks: Anglo-Indian Diplomacy on the Southern Frontier, 1733-1763, Gainesville, The University Press of Florida, 2010.

Kappler, Charles J. (ed.), Indian Affairs. Laws and Treaties. Vol. II: Treaties, Washington D. C., Government Printing Office, 1904.

Levaggi, Abelardo, «Aplicación de la política española de tratados a los indios de la Nueva España y sus confines: el caso de la Luisiana y las Floridas (17911798)», Anuario Mexicano de Historia del Derecho, 10, Ciudad de México, 1998, 449-483.

Levaggi, Abelardo, Diplomacia hispano-indígena en las fronteras de América. Historia de los tratados entre la Monarquía española y las comunidades aborígenes, Madrid, Centro de Estudios Políticos y Constitucionales, 2002.

Martínez Díaz de Guereñu, Ernesto, Regalos, favores y donación de órganos. Ensayo exploratorio de doremática, Bilbao, Universidad de Deusto Digital, 2011.

Mauss, Marcel, Ensayo sobre el don: forma y función del intercambio en las sociedades arcaicas, Buenos Aires, Katz, 2009 [1. a ed. 1925].

Milanich, Jerald T., Laboring in the Fields of the Lord: Spanish Missions and Southeastern Indians, Washington, Smithsonian Institution Press, 1999.

O'Brien, Greg, Choctaws in a Revolutionary Age, 1750-1830, Lincoln, University of Nebraska Press, 2002.

Pratt, Mary Louise, Ojos imperiales. Literatura de viajes y transculturación, Ciudad de México, Fondo de Cultura Económica, 2010 [1. a ed. 1992]. 
RAE (Real Academia Española), Diccionario de la Lengua Española, 23. a ed. [versión 23.4, actualización 2020, en línea], Madrid, Real Academia Española, 2014. Disponible en: https://dle.rae.es [Consultado: 13/01/2020].

Ratto, Silvia, «El debate sobre la frontera a partir de Turner. La New Western History, los Borderlands y el estudio de las fronteras en Latinoamérica», Boletín del Instituto de Historia Argentina y Americana Dr. Emilio Ravignani, 24, Buenos Aires, 2001, 105-140.

Schröter, Bernd, «La frontera en Hispanoamérica colonial: un estudio historiográfico comparativo», Colonial Latin American Historical Review, 10:3, Albuquerque, 2001, 351-385.

Spicer, Edward H., Cycles of Conquest: The Impact of Spain, Mexico and the United States on the Indians of the Southwest, 1533-1960, Tucson, University of Arizona Press, 1962.

Taylor, Lawrence Douglas, «El concepto histórico de la frontera», en Olmos Aguilera, Miguel (coord.), Antropología de las fronteras, México, El Colegio de la Frontera Norte, 2007, 231-261.

Turner, Frederick Jackson, The Frontier in American History, Nueva York, Henry Bolt \& Co, 1920.

Weber, David J., «Turner, the Boltonians, and the Borderlands», The American Historical Review, 91:1, Oxford, 1986, 66-81.

Weber, David J., «Borbones y bárbaros. Centro y periferia en la reformulación de la política de España hacia los indígenas no sometidos», Anuario IEHS. Revista del Instituto de Estudios Histórico Sociales Prof. Juan Carlos Grosso, 13, Tandil, 1998, 147-171.

Weber, David J., Bárbaros. Los españoles y sus salvajes en la era de la Ilustración, Barcelona, Crítica, 2007.

Weeks, Charles A., Paths to a Middle Ground: Natchez, Boukfouca, Nogales, and San Fernando de las Barrancas, Tuscaloosa/Londres, The University of Alabama Press, 2005.

White, Richard, The Middle Ground. Indians, Empires and Republics in the Great Lakes Region, 1650-1815, Nueva York, Cambridge University Press, 2011. 